\title{
Benefit Relationships in the Process of Turning the College Students into Profes- sionals in China
}

\author{
De Jun Zou ${ }^{1}$ \\ ${ }^{1}$ Guangdong Industrial and Commercial College; Guangzhou; 510510
}

\begin{abstract}
The process smoothly turning the college students into professionals is very important for the community In China. Employee's income is the main part of the cost of the employer hire the employees. so, the employer's benefit conflict with the student's benefit In this process, The only solution is the college students to create more value. The college students competitive advantage lies in high-end industrial chain. Therefore, the industry should upgrade as soon as possible in China.
\end{abstract}

Keywords: student, benefit, professional

\section{Introduction}

Now, the most significant source of professionals are college students in china. With the social and economic development, China popularize nine-year compulsory education. Many families have adequate financial resources to support kids with college. In the summer of 2013, China has nearly 700 million college students graduating from the university[1]. After graduating from college, students engaged in a specific occupation. They gradually become a new force in professional positions. Position turning from college to professionals is an important stage for college students. A large number of students successfully transforming into professionals plays an important role for social stability and development. Analysis factors of benefit relation in the process turning college students into professionals, streamline benefit sharing and promote more efficient in the process. The quality of the process of college students being into the professionals has an important impact on business, regional and national competitiveness.

The benefit Always subordinate to a person or a particular entity. Therefore, before analyses the benefit relations of certain professional competence requirements, must distinguish firstly stakeholders involving such occupation. Professionals is the worker engaged in the types of concrete work. In the modern market economy, the transaction is a basic form of the allocation of resources, and professionals get jobs by the market. Labor supply and demand sides in the talent market make full consultation for specific content of the work, such as time and pay[2], and form a labor contract. Employers will assess whether the professionals have the specific ability to complete the work of the labor contract. In order to get a job or get a better job benefits, People will develop capacity in accordance with the higher professional treatment. Enterprises and other economic organizations is a major employer in market economy. Enterprises and other economic organizations have to provide goods and services to meet customer needs, then achieve its target. In order to meet customer and other demander for 
such goods and services objects, enterprises and other economic organizations must use advanced technology, organization and management to produce and deliver products and services. The technical and organizational management dependent on the overall socio-economic situation. Although there may be different that each person engaged in an occupation specific work because specific work environment, such as environmental organizations, local special cultural factors are different. However, the contents and competency requirements of each category of profession exist in common[3]. These are based on each type of professions in the market economy are around certain aspects of the products and services to meet the specific needs. Therefore, the common needs of the community makes similar professional positions with the same or close to the professional competence requirements.

Professional as a product of social activities have complex benefit relations. These benefit relations not owned by a single subject, such as enterprise. These benefit relations should be the social scale, and a wide variety of body together constitute. The main benefit relations come together, form a mutual influence decisions required by professional people working together. Therefore, turning the students into the professional people in the process involves many different kinds of benefit relations.

\section{Analysis of the Factors of the Bene- fit Relation in the Process of Turn- ing the College Students into Pro- fessionals in China}

The major stakeholders directly involved in the process turning students into professionals include students, schools and employers. the main body are college student. In the process turning students into professionals. Students as recipients of education, are the potential for professionals in the future, and have directly benefit relations with schools and employers. The benefit relations about students and colleges include: colleges charge a tuition fee from students, and college get funding and resources from government and community donations; at the same time, college organize educational resources and teaching activities to make students promote the certain cultural qualities and professional skills. If the college and students are the seller and buyer as a trading point of view, students are the demand side of educational and teaching services, and colleges are the supply side. In order to achieve a higher education quality, colleges and students need to cooperate for a long time. In the process of cooperation, students and colleges will form a good friendship.

In most cases, tuition fees paid by students are insufficient to cover the full cost of educational and teaching services. From the trading point of view, the colleges providing the educational and teaching services are losing money. In other words, students derive externality benefits. Of course, the colleges get government grants and other ways to make up the remaining costs. In this regard, most colleges have a certain nature of public goods. Therefore, the benefit relationship between the colleges and students is not a simple supply and demand, but rather a complex cooperation relationship. It can be said that trading relationship with the colleges and students put on the cloak of morality, also can be said that the moral relationship with the colleges and students put on the cloak of the transaction.

Students and employers also exists between direct interest in the process turning college students into professionals. In the current teaching setting, the benefit relationships between students and employers are located in the second half of 
the process, including the near time before the graduation or a year to six months probation before they become the professionals. At this stage, students have mastered certain skills, has engaged in certain occupations, positions, especially basic technical work, but cannot complete a specific job because they have not an independent professional competence of all. there is a big gap between students and professionals. Based on the time Pointed in the students graduate from college, this stage can be divided into two parts. Before graduation, the students as an intern provide labor services for the employers, and the employers must be paid for students work and to give students the places and the environment to learn professional competence training and to gather experience. After graduation, the students as a professional provide labor services for the employers, and the employers must give students wages, social status, job opportunities for promotion and other relevant compensation. Therefore, there are both an employment relationships and vocational training relationships between students and employers in the process. The employer has the function of education to some extent, play the role as the teachers of the colleges.

At this stage of the market environment, companies play the role of personnel training is an inevitable move. Colleges teaching purpose is to make students get the foundation and potential of the career development. So college students choose their own career development in the future. The educational and teaching environment and culture in the colleges are not exactly as the same as professional work environment and culture in the employers. After employing the students, the employer need to do vocational training for the students according the their appropriate characteristics. The vocational training include new staff for cultural development that is condu- cive to the employer. The purpose is to obtain more suitable professionals for the development of the employer. Employers to recruit for their own development needs students as new employees, and train them. Overall, the benefit relationships between the college students and the employer is controlled by the labor contract.

Parents are also important stakeholders in the process turning students into professionals. Parents importantly influence on students' career choices. Parents give students when they need a major capital investment and emotional care to grow. Relationship between parents and students performance altruistic mode. Since the close relationship between parents and students to each other, can often be used as a community of benefit to be treated the same.

Student's main destination become the professionals for the employer after the process turning the students into professionals. So the mutual benefit relationships of the employers and the students in and after the process has an important impact on their behavior. Because the employer did not accept to be college students and university education personnel comparison, it is necessary to analyze the relationship between the interests of the general employment process.

It is necessary to analyze the process of the interests of the general employment relationship, because employers want to compare the pros and cons of hiring college students and other persons who did not get a college education.

Employers are required to pay a certain cost in the process hiring any personnel. These are such as recruitment, training new staff personnel and office expenses, staff wages and post-employment benefits. These referred to as the employer hiring costs, market as EHC. In comparison, wages and benefits accounted for the vast majority of employers hiring costs. 
Employee's income is the main part of the cost of the employer hire the employees. Then, the employee benefits are closely linked to the EHC. Employers derive revenue primarily involved in the production of staff activities value. This is referred to as the employer employment income, market as EEI. The employer would consider hiring professional people if the EEI is more than EHC. The balance between the EEI and the EHC is the employer's employment profits, market as EEP.

When employers hire professionals, employment costs given is different, so it will produce a different employment income. The cost of hiring professional personnel and their revenues are connected together, constitute a yield curve of the employment costs. Yield curve of the employment costs can completely describe the employment relationship between employer's employment income and costs.

Because of the restraint of the statutory minimum wage, the wage and the reward that the employees get from the employer can not be any less than the statutory minimum wage. Under normal circumstances, the employees who are given more rewards can be motivated to work harder. These will increase EEI. EEI increased to different degrees in various EHCs that are based on increasing the compensation of employees to enable employees to work actively.

Under normal circumstances, a slight increase in employee compensation in the minimum wage cannot make the employee motivation to increase dramatically. Corresponding, EEI increase relatively lower. When the returns that the employee increase largely, employees can be motivated to do their best. It increase the EEI greatly.
Since the limitations of employee's ability or the decrease of the compensation incentive if the employee compensation increase up to a certain extent, the EEI of increase gradually reduced, until no further increase.

When employers need to hire professional person, the employer can choose the employees between the college students and other persons did not receive college education. The condition that attract college students to participate in the process turning themselves into the profession it the student's EEP more than the total of the other person's EEP and the costs of college education. If this condition does not exist, then the people will probably not go to college in the future. If not only the employer obtain EEP that hire the college students than the other groups, but also to let the students receive high wages and benefits, it mean that the employer can afford the cost of hiring a high enough for college students, then there is only way that the EEP students create is more than the college education fee and the other person that did not get the college education. Meanwhile, the students are better educated, more capable technology to deal with more complex things.

\section{References}

[1] http://career.eol.cn/kuai_xun_4343/20 130129/t20130129_898345.shtml

[2] Bauer, T.N., Morrison. Research in Personnel and Human Resources Management, Vol.16,(1998)149-214.

[3] Tanya Li, Jianqiao Liao (in Chinese), Industrial Engineering and Management, Vol. 6: (2005) 100-103 